\title{
Mulheres negras no audiovisual brasileiro
}

\author{
Cleonice Elias da Silva*
}

Resumo: Este artigo corresponde aos resultados iniciais de uma pesquisa sobre as mulheres no cinema brasileiro como diretoras, a qual, quando finalizada, será publicada em livro. Nele apresento um breve panorama sobre a participação das cineastas negras no cenário cinematográfico brasileiro, chamo a atenção pela ausência de uma diversidade de gênero e étnica nesse cenário.

Palavras-chave: mulheres negras; cineastas; cinema brasileiro.

Resumen: Este artículo corresponde a los resultados iniciales de una investigación sobre las mujeres en el cine brasileño como directoras, la cual, cuando finalizada, será publicada en libro. En él presento un breve panorama sobre la participación de las cineastas negras en el escenario cinematográfico brasileño, llamo la atención por la ausencia de una diversidad de género y étnica.

Palabras clave: mujeres negras; cineastas; cine brasileño.

Abstract: This article corresponds to the initial results of a research on women in Brazilian cinema as directors, which, when finalized, will be published in a book. In it I present a brief overview of the participation of black filmmakers in the Brazilian cinematographic scene, I draw attention to the absence of a gender and ethnic diversity in this scenario.

Keywords: black women; filmmakers; brazilian cinema.

Résumé : Cet article correspond aux premiers résultats d'une recherche sur les femmes dans le cinéma brésilien en tant que réalisatrices, qui, une fois finalisée, sera publiée dans un livre. Dans ce document, je présente un bref aperçu de la participation des cinéastes noires sur la scène cinématographique brésilienne. J'attire l'attention sur l'absence de diversité sexuelle et ethnique dans ce scénario.

Mots-clés : femmes noires ; cinéastes ; cinéma brésilien.

* Pontifícia Universidade Católica de São Paulo, Faculdade de Ciências Sociais, Programa de Pós-Graduação em História Social. 05014 -901, São Paulo, Brasil. E-mail: cleoelias28@gmail.com

Submissão do artigo: 12 de dezembro de 2017. Notificação de aceitação: 1 de março de 2018.

Doc On-line, n. 23, março de 2018, www.doc.ubi.pt, pp. 46-61. 


\section{Adélia Sampaio}

Não teria como escrever sobre as mulheres cineastas sem dar a devida atenção para o fato de que é quase inexistente a presença de diretoras negras no cinema brasileiro. A pioneira nesse campo é a mineira radicada no Rio Janeiro, Adélia Sampaio, que recentemente vem ganhando o merecido reconhecimento pela sua trajetória como cineasta, produtora e como mulher negra de família humilde, que conseguiu as duras penas driblar os limites de ascensão social que são impostos àqueles que são pobres. No caso de Adélia, as dificuldades foram maiores, pois ela não era apenas pobre, mas também mulher e negra.

Tive a oportunidade de conhecê-la pessoalmente em julho de 2017, pessoa muito agradável e solicita, de um senso de humor imensurável e contagiante. Sua formação como cineasta, segundo a própria, deu-se dentro dos sets de filmagem. Por intermédio de sua irmã, Eliana Cobbett, produtora de cinema, conseguiu um emprego como telefonista na Difilm, ${ }^{1}$ na segunda metade da década de 1960. Então, a história de Adélia Sampaio embolou-se com a história do Cinema Novo, ela conviveu com o grupo de cineastas idealistas, que romperam com os padrões vigentes na cinematografia brasileira marcada pela produção dos grandes estúdios. O seu desejo de se tornar cineasta surgiu após assistir ao filme Ivan, o Terrível (Sergei Eisenstein, 1944). Compartilhou o desejo de dirigir filmes apenas com sua irmã. Todavia, Adélia teve que adiar um pouco o projeto de se tornar diretora de cinema para cuidar dos seus dois filhos, seu marido na época, membro do Movimento Revolucionário 8 de Outubro (MR-8), foi um preso político da ditadura civil-militar brasileira. Adélia também chegou a ser presa, mas ficou apenas três dias na prisão, na época tinha apenas vinte e um anos, e seu marido vinte e três. Ela militou na Liga Camponesa.

Adélia criou laços de amizades com algumas pessoas que tinham uma atuação no cinema nacional, entre eles, José Medeiros e o Dib Lutfi, que eram grandes fotógrafos da época. Aos poucos foi trilhando sua trajetória no campo do cinema. Primeiro fez um curso de continuísta, e fez a continuidade de dois curtas-metragens, depois foi especializando-se em produção. Trabalhou em cinco filmes como assistente de produção, e foi a responsável pela direção de produção do filme O Seminarista (Geraldo Santos Pereira, 1977), este foi o primeiro filme da atriz Louise Cardoso. Também teve a oportunidade de trabalhar com Rafael Valverde. Com ele, Adélia aprendeu muitos aspectos sobre a edição de filmes, segundo ela:

1. A Difilm (Distribuidora de Filmes Brasileiros Ltda) foi criada em 1965, sua função era a distribuição dos filmes dos cineastas do Cinema Novo. Nelson Pereira dos Santos e Luís Carlos Barreto foram os principais articuladores da produtora. 
Ele era considerado um bam-bam. Tive esse prêmio na vida! E aí o Zé disse: "Eu vou falar com Rafael Valverde para ver se ele te deixa ficar na moviola." E aí, eu fui, me tornei grande amiga de Rafael e virei meio que uma assistente quebra galho, que aí ele tinha menos trabalho. Eu ia para moviola mais cedo, selecionava os fotogramas pendurava, quando ele chegava, era só (...). E com isso, você descobre o que é o pulo do gato do cinema (...).

Seu primeiro trabalho como diretora foi realizado após ela sair da Difilm, foi um curta-metragem, Denúncia vazia (1979), neste mesmo período Adélia abriu uma pequena produtora. O curta é baseado em uma história verídica de um casal de idosos que cometeu suicídio após receber a denúncia vazia, que é a retomada de um imóvel pelo seu locador. O curta contou com a atuação do ator Rodolfo Arena. Adélia mostrou o seu curta a Mário Falaschi, italiano que deu muito apoio aos cineastas do Cinema Novo. O primeiro curta-metragem de Adélia foi exibido no Cinema Palácio, alcançou uma boa receita que possibilitou que ela realizasse outros curtas. A lei do curta-metragem ${ }^{2}$, que incentiva esse tipo de produção, propiciou que alguns cineastas iniciassem suas carreiras com a realização de curtas-metragens.

Nos anos seguintes, ela dirigiu outros curtas-metragens: Adulto não brinca (1980), Agora um Deus dança em mim (1981) e na Poeira das ruas (1982).

E aí, não tinha mais jeito, começou o boca, boca: "Adélia agora resolveu que vai dirigir! Vai dirigir!". E eu comecei a fazer os meus curtas, que não tinha, e aí como é que eu fiz meus curtas? Como eu tinha uma estreita amizade com os assistentes de câmera, e assistente de câmera é que corta o negativo, chassis, não é da sua época, mas chassis, a lata do filme, você sabe, né? Então, sempre que cortava sobravam pontas, eles me davam. Eu fiz muito filme de ponta, que aí você põe na geladeira, condicionado, conserva o negativo. E aí, eu comecei a elaborar outros curtas com o objetivo de fazer um longa.

Antes de realizar dois dos curtas-metragens citados, assumiu a produção de um filme dirigido por José Medeiros, Parceiros da Aventura (1980), do filme de Lulu de Barros, ${ }^{3}$ Ele, Ela, Quem? (1980). Para o filme de José Medeiros, que ela chama de Zé Medeiros, foi montada uma equipe técnica composta por uma maioria de negros e o elenco também contou com a participação de atores e atrizes negras. Tratando-se do filme de Lulu Barros, que na época da

2. A legislação referente ao incentivo da produção de curtas-metragens data da década de 1930. Um Decreto-Lei de 1932 criou uma taxa cinematográfica para a educação popular, os recursos provenientes dos filmes estrangeiros viabilizaria a produção de curtas brasileiros de cunho educacional. A "Lei do curta" citada no texto foi criada em 1975 e possibilitou o surgimento de um mercado para a produção e distribuição de filmes de curta-metragem no país. A lei obrigava as salas de cinema exibirem um curta-metragem brasileiro antes das sessões de filmes estrangeiros.

3. Cineasta carioca cujo nome de registro é Luiz Figueiredo Teixeira de Barros, nasceu em 1893. Ele dirigiu filmes no período do cinema mudo e posteriormente. Seus filmes conquistaram uma popularidade significativa, entre eles as comédias musicais. Ele faleceu em 1981, aos 88 anos. 
realização estava com 87 anos de idade, Adélia afirmou que ele havia pedido financiamento à Embrafilme, mas não obteve retorno. Circulou uma história de que Roberto Farias não aprovou o financiamento por medo de Lulu de Barros morrer antes de terminar o filme. Ao saber disso, o cineasta levou até Roberto Farias uma série de exames, que mostravam que a sua saúde estava boa. Adélia narra com detalhes esse acontecido:

(...) E aí, ele me contou que ele deu entrada na Embrafilme já há quatro anos, ninguém respondeu. E aí, teve uma história louquíssima, porque alguém falou para ele que o Roberto não daria o financiamento para ele porque ele podia morrer. E aí, o que ele fez? Ele fez disso uma limonada, cara! Ele foi para o médico encheu uma 007 de exames, chegou na sala do Roberto: "Seu Roberto!" "O quê é isso!?" "Isso aqui é meu coração! (...) Agora falta o que para me dar o financiamento?!" (...). Aí o Roberto pediu que ele encontrasse uma empresa cujo o titular fosse diretor de produção. Adélia! Só tinha eu mesmo! Aí aparece o Mário com o Lulu, que para mim foi muito bonito fazer um filme dele porque ele era um cara que não usava copião. Ele montava no negativo. Toda uma técnica absolutamente (...) ele usou a equipe técnica dele, que somando dava setecentos anos todo mundo! Era uma loucura! Tinha ambulância na porta. E aí, ele fez o filme. A história da cabeça dele. E o filme ficou pronto. E o Roberto disse: "Você é muito sortuda!" "Não, cara! Se desse alguma merda com ele, eu ia terminar o filme!" "Como?" "Porque eu vou dirigir um longa!" (...)

Então, Adélia colocou em prática o seu antigo projeto de dirigir um longametragem. Contou com a colaboração do jornalista José Louzeiro para escrever o roteiro de Amor Maldito ${ }^{4}$ (1984). Louzeiro teve acesso aos autos de tribunal, Adélia disse que para o jornalista utilizar esses autos para a elaboração do roteiro seria um meio de mostrar ao público a "violência do tribunal de forma real". Adélia convidou José Medeiros para ser o diretor de fotografia do filme, mas ele recusou. Ele deu a seguinte justificativa à cineasta: "Adélia, eu posso até dirigir o seu filme, mas eu acho quem tem que dirigir seu filme é quem está começando, sabe por quê? Eu faço o filme, e as pessoas vão dizer que o filme ficou bom porque fui eu que fiz! Então, olha o conselho de amigo!". Diante da recusa do amigo, Adélia convidou Paulo César Mauro, que já havia realizado a direção de fotografia de seus curtas-metragens.

O filme foi realizado por meio de um sistema de cooperativa. O financiamento para a sua realização foi concedido por uma engenheira chefe de Furnas. Ela ficou sabendo do trabalho de Adélia quando esta dirigiu um espetáculo teatral com os funcionários da empresa. A engenheira nem quis ler o roteiro antes de dar o dinheiro para Adélia poder realizar o filme.

4. O roteiro do filme foi finalizado em 1974, mas Adélia Sampaio levou quase quatro anos para viabilizá-lo. 
Em linhas gerais, Amor maldito apresenta em sua narrativa uma relação homossexual entre duas mulheres. O filme participou e participa de festivais, cuja temática são as questões do movimento LGBT, entre eles, o San Francisco International Lesbian \& Gay Film Festival. Ele foi filmado em apenas três semanas, e uma de suas locações foi o tribunal de Niterói.

$\mathrm{Na}$ época em que realizei a entrevista com Adélia Sampaio, 11 de julho de 2017, ela estava envolvida em dois projetos de filmes, ambos de ficção, mas que têm os seus roteiros baseados em situação verídicas. Meu nome é Carretel, um curta-metragem, é a história de um menino de uma comunidade, que foi criado com afeto e carinho pela família. Ele arruma um emprego com entregador de farmácia. Em sua segunda entrega, ele é humilhado por uma mulher. Furioso com a situação joga na mulher o carretel com linha de cerol, que sempre carrega no bolso, acaba sendo preso, foge logo depois. O menino sem perspectivas envolve-se com o tráfico de drogas no morro. O outro é um longa-metragem ambientado no período da ditadura civil-militar, A barca das visitantes, sobre as visitas aos presos políticos no antigo presídio da Ilha Grande. O roteiro tem como referência as cartas que recebeu de seu então marido enquanto esteve preso.

Para Adélia Sampaio, é muito importante falar da ditadura civil-militar, pois há jovens que desconhecem esse passado do nosso país. Ela presenciou uma situação na qual um grupo de jovens falava que a série exibida pela rede Globo em 2017, Os dias eram assim, trata-se de apenas mais uma ficção. Nesse sentido, o meio audiovisual pode contribuir para trazer à tona aspectos do período do governo dos militares.

Adélia Sampaio participou e participa de diferentes eventos pelo Brasil afora sobre cinema, alguns deles com objetivo de divulgar o trabalho das cineastas negras. Conforme o mencionado, ela é a primeira cineasta negra do cinema brasileiro. Ela afirma que sempre foi "inteiramente negra": "Eu não sou negra hoje! Sempre fui, entendeu? Uma consciência muito grande dos valores, do que se deve a minha raça (...)”. O relato de Adélia diz respeito ao processo de autoafirmação dos negros, é possível afirmar que as conquistas oriundas das lutas do movimento negro vêm contribuindo com tal situação.

Relatou-me uma situação que vivenciou em um evento para o qual foi convidada, realizado na cidade de Tiradentes, de uma jovem que lhe disse que resolveu fazer cinema por causa dela:

Por exemplo, lá em Tiradentes uma plateia de umas cento e poucas pessoas, de repente levantou uma menininha, ela deve ter uns vinte e poucos anos, ela está estudando cinema. E ela disse: "Eu vim aqui porque eu queria te dizer uma coisa que eu não posso guardar comigo!" E eu digo: "O que que é?". "Desde que eu nasci, eu procuro um espelho para eu olhar, e achei em você 
meu espelho!”. Eu desabei! Eu desabei! Olhei para ela: “Vai em frente!”(...). Não é nada de ego, é uma coisa mais profunda, entendeu?

Merecidamente Adélia Sampaio vem se tornando um exemplo e inspiração para jovens aspirantes a cineastas, sobretudo para as mulheres negras. Relatoume que um de seus netos ficou sabendo a respeito de sua trajetória no cinema sozinho, por meio de notícias que leu na internet. Tratando-se da história da participação das mulheres como diretoras de cinema no Brasil, Adélia Sampaio ocupa um lugar importante, e sua trajetória deve se tornar conhecida não apenas por aqueles que querem seguir carreira de cineastas, mas por todos nós.

$\mathrm{Na}$ atualidade, ela gosta dos trabalhos da jovem cineasta Yasmin Thayná, gostou do resultado do filme de Lúcia Veríssimo, Eu, meu pai e cariocas (2017) e do filme de Leandra Leal, Divinas Divas (2017). Das produções nacionais mais antigas, diz gostar do filme Que bom te ver viva (1989), de Lúcia Murat $e$ Gaijin, caminhos da liberdade (1980) ), de Tizuka Yamasaki.

Acredita que na atualidade o trabalho cinema está mais fácil, o acesso a bons equipamentos possibilita o trabalho de muitos cineastas. Todavia, não lhe agrada a política atual dos editais de financiamento das produções audiovisuais.

Concordo com Adélia Sampaio quando ela afirma que fez sua parte, e diria mais, ela continua fazendo parte da história do cinema nacional, seja através da realização de novos projetos, seja participando de eventos pelo Brasil inspirando jovens cineastas.

Eu acho que eu fiz a minha parte (...). Se foi doído, sacrificado (...) mas eu fiz! E me considero uma pessoa vitoriosa, porque eu vim daqui. E cheguei! E isso tem que ter a ver muito com a verdade da minha mãe. Mamãe era uma pessoa que imprimia uma coisa forte, e que nos fez forte!

\section{Viviane Ferreira}

Viviane Ferreira é a diretora do curta-metragem Um dia de Jerusa (2014), exibido no Festival de Cannes de $2014^{5}$, estrelado por Léa Garcia e Débora Marçal. O curta inspirou a realização de um longa-metragem com o mesmo nome. Viviane Ferreira é cineasta e advogada é a segunda diretora negra a realizar um longa-metragem no país, depois de Adélia Sampaio. Tal fato mostra como o cenário cinematográfico brasileiro expressa uma grande desigualdade. Conforme mencionado anteriormente, é quase inexistente a presença de diretoras negras, irei discutir essa realidade mais adiante.

5. Ceiça Ferreira e Edileuza Penha Souza mencionam que nesse mesmo festival, em 2014, foi exibido o curta-metragem $O$ tempo dos Orixás (2013), dirigido por Eliciana Nascimento, cineasta também nascida na Bahia e negra (Ferreira; Souza, 2017: 181). 
Viviane Ferreira nasceu na periferia de Salvador, em Coqueiro Grande. Ela é uma ativista engajada com os movimentos das mulheres negras. Sua formação política foi influenciada pela sua vivência religiosa no candomblé, onde o feminino ainda é centro do poder. Sua formação como cineasta tem como referências o cinema de Zózimo Bulbul e Glauber Rocha. Dirigiu os seguintes documentários até o momento: Dê sua ideia, debata (2008); Festa de mãe negra (2009); Marcha noturna e peregrinação (2016). Seu primeiro filme de ficção foi o curta experimental Mumbi 7 cenas pós Burkina (2010), estrelado por Maria Gal e o já mencionado Dia de Jerusa (2014). A cineasta foi presidente da Associação Mulheres de Odun, organização de mulheres negras feministas, até 2017, é sócia-fundadora da empresa Odun Formação \& Produção e presidente da Associação dos Profissionais do Audiovisual Negro (APAN).

Em entrevista concedida à filósofa Djamila Ribeiro, pulicada no dia $1^{\circ}$ de setembro de 2017 pela Carta Capital, afirmou que é uma responsabilidade muito grande ser a segunda cineasta negra no Brasil que dirigiu sozinha um longa-metragem. Viviane Ferreira quebrou um "jejum histórico na cinematografia brasileira", lembrando que o Amor maldito, de Adélia Sampaio, foi lançado em 1984.

Ela defende a importância de editais de cunho afirmativo para o incentivo e viabilização de produções audiovisuais de negros e negras. Esse seria um meio possibilitado pelo Estado brasileiro, este marcado por uma grande desigualdade racial, para viabilizar as produções desses sujeitos, dando oportunidades para que esses contem suas histórias.

É um fato incontestável que a sociedade brasileira vive uma história de profunda desigualdade racial. De mesmo modo, é incontestável a necessidade de esforços do Estado brasileiro para propor políticas reparatórias que visem reduzir esse fosso de desigualdades.

Por isso, os editais curta e longa afirmativos são importantes por serem reveladores de uma demanda reprimida: há pessoas negras sedentas por contar a própria história. (Ribeiro, 2017).

Para ela, os editais atuais têm alguns critérios excludentes racialmente. Para mudar essa situação afirma como é importante que a ANCINE construa em diálogo com a Secretaria do Audiovisual e a sociedade civil um Panorama Nacional de Ações Afirmativas para o Setor Audiovisual. Não há como discordar da afirmação da cineasta de que existe no Brasil uma necessidade de reparação histórica e simbólica à população negra, cabendo ao Estado essa função. As produções audiovisuais têm que ser mais representativas da realidade social e cultural do nosso país, uma vez que os negros e negras correspondem à metade da população brasileira. Nas palavras de Viviane Ferreira: "O Programa 
Nacional de Políticas de Ações Afirmativas para o Setor Audiovisual é elemento indispensável para o avanço e aprimoramento das políticas audiovisuais brasileiras e, consequentemente, para o fortalecimento do cinema nacional" (Ribeiro, 2017).

Ela admite o quanto trabalha para que o contexto atual da cinematografia brasileira conte com uma maior participação dos negros, principalmente, das cineastas negras.

Hoje, meu dia precisaria ter 48 horas. As regras do jogo para tornar esse sonho realidade não são tão nítidas para pessoas negras quanto às regras do Brasileirão para o futebol. Eu preciso me dedicar 24 horas à contribuição da elaboração dessas regras, para que caibam corpos e mentes negras no jogo. As outras 24, para redigir minhas narrativas e percorrer o árduo caminho de tentar garantir que os sonhos de filmes se tornem realidade (Ribeiro, 2017).

\section{Outras cineastas negras}

Cabe mencionar o trabalho de outras cineastas brasileiras negras, entre elas Sabrina Rosa, que assina a direção do filme Vamos fazer um brinde (2011) com Cavi Borges, e Glenda Nicácio, que dirigiu com Ary Rosa o filme Café com canela (2017). Filme que recebeu dois prêmios no $50^{\circ}$ Festival de Brasília: melhor filme pelo júri popular e melhor roteiro.

O filme da atriz e cineasta Sabrina Rosa e de Cavi Borges foi realizado com um baixo orçamento e foi premiado no Festival Cine PE. Com o filme Sabrina Rosa pretendeu expressar o que pensa sobre as mulheres de sua geração e como a independência das mesmas mudou suas relações (Fonseca, 2010).

Glenda Nicácio afirma que vem sendo uma realizadora negra no Recôncavo da Bahia. Para mesma, não há como se fazer cinema sem levar em consideração o lugar de fala. Em suas palavras: “(...) afinal, dá pra fazer cinema sem considerar a história de um país?" (Nicácio, 2017). Ou seja, o fato de ser uma mulher negra marca a sua produção cinematográfica, uma vez que ela corresponde a outras narrativas que por muito tempo não tiveram espaço no referido meio.

(...) Estou falando dessas e de outras tantas zonas periféricas que, não de repente e não por acaso, estão articulados criando novos modos de produção e narrativas plurais tecidas por que sempre esteve à margem. (...) narrativas esquecidas, saqueadas, aniquiladas (por quem?) - na história de um cinema. Essa história que fala de, mas que poucas vezes falou para mim e para os meus." (Nicácio, 2017).

Para ela, essas produções redirecionam o olhar. É um cinema que parte do outro, "que se potencializa nas brechas que foram deixadas" Glenda Nicácio afirma que não há como falar de seu trabalho como cineasta sem falar em 
vivências e que a sétima arte é uma forma de sobrevivência: "Eu, hoje não me esqueço que cinema é sobrevivência. E nesse sentido, é urgente seguir, e buscar a imagem que permita o desvelamento de vidas que extrapolam o que o próprio cinema previu." (Nicácio, 2017).

Larissa Fulana de Tal é outra jovem cineasta da Bahia, formou-se na Universidade Federal do Recôncavo Baiano. Criou juntamente com amigos produtores o coletivo Tela Preta, em 2010. Seu primeiro filme de ficção foi o curta-metragem Cinzas (2015), baseado no conto homônimo de Davi Nunes, dirigiu também o documentário Lápis de cor (2014). Para Larissa Fulana de Tal, o coletivo possibilita que suas reivindicações sejam postas em prática.

A gente percebeu o quanto era imenso esse universo [do cinema]. E chegou o momento em que nossas reivindicações fossem concretizadas em propostas. Não adiantava mais o diagnóstico de que o cinema é racista, não adiantava mais o diagnóstico de que não é possível para a gente, de que o acesso é difícil. Daí de 2010 para cá teve o Lápis de Cor, que foi uma chamada que ganhamos do Canal Futura, teve o Canções de Liberdade, que foi o primeiro filme com o selo Tela Preta e em 2012 ganhamos dois editais. (Neto, 2015).

O seu trabalho está intrinsicamente ligado à sua afirmação como mulher negra. As ideias de bell hooks tiveram um papel fundamental para a sua conscientização como mulher negra. O seu nome artístico foi inspirado em um livro chamado Noites dos Cristais, que pegou emprestado de seu tio. A autoria da obra é de Luis Fulano de Tal e é uma novela histórica sobre a Revolta dos Malês. Os escravos sem donos recebiam os sobrenomes: Fulanos, Beltranos e Ciclanos (Neto, 2015).

Yasmin Thayná nasceu em 1992, em Nova Iguaçu, na Baixada Fluminense do Rio de Janeiro, cresceu na Vila Iguaçuana, em Santa Rita. Desde jovem tem interesse pela escrita, estuda comunicação social na PUC-Rio. Começou a realizar curtas-metragens com 16 anos. Em seu curta-metragem Kbela (2015) retrata o processo de aceitação das mulheres negras, em suma, o filme traz à tona a questão da identidade da mulher negra. O elenco foi formado por atrizes negras e uma mulher trans. O filme Alma no olho (Zózimo Bulbul, 1974) foi uma inspiração para ela uma vez que a cineasta optou em dar ao seu curta um aspecto experimental.

Sabrina Fidalgo nasceu e cresceu no Rio de Janeiro, estudou cinema na Escola de TV e Cinema de Munique, na Alemanha, e especializou-se em roteiro na Universidad de Córdoba, na Espanha. Ela é dona da produtora Fidalgo Produções. A questão negra está presente em seus filmes, mas suas obras abrangem outras temáticas. Iniciou sua carreira com a realização de curtasmetragens, o primeiro deles foi Sonar 2006 - Special Report (2006), depois dirigiu Das Gesetz des Stärkeren (A lei do mais forte, 2007) . A partir de 
Black Berlim (2009) começou a tratar mais diretamente de temáticas relacionas à questão social, racial e de gênero. Cinema mudo (2012), Personal Vivato (2014), Rainha (2016) são outros curtas-metragens dirigidos pela cineasta, dirigiu o documentário musical de média-metragem para televisão Rio encantado (2014) e vários videoclipes. O projeto de documentário Cidade do Funk também é de sua autoria.

Em Rainha a cineasta apresenta uma discussão sobre a imposição dos padrões de beleza da qual as mulheres são vítimas. Segundo Sabrina Fidalgo:

Há muita gente ganhando dinheiro com a propagação desse tipo de alienação e, claro, são sempre as mulheres as primeiras vítimas e as que sofrem as piores consequências. Crianças já se preocupam com seus corpos como se fossem mulheres de 35 anos e isso é apenas o início do fim. O corpo feminino é uma moeda de troca no Brasil tanto para a mulher quanto para o homem. Se a mulher tem um corpo que se encaixa dentro dos padrões estabelecidos, ela tem uma moeda de troca poderosa com a qual pode obter privilégios sociais e pessoais. Se um homem (dentro ou fora desses mesmos padrões) tem uma mulher que se encaixa nesses padrões a seu lado, isso se torna um símbolo de status. (Ribeiro, 2016).

Apresenta críticas à indústria do carnaval, a qual promove a elitização e a perda do protagonismo negro no evento. Ela considera que a figura da Globeleza expressa a coisificação do corpo da mulher negra. Todavia, tem uma opinião diferente a respeito das rainhas de bateria.

A rainha da bateria, ao contrário da figura da Globeleza, por exemplo, não é uma figura submissa e nem objetificada. Ela é uma rainha, uma mulher de atitude, ela é a mulher poderosa que representa a escola e esta à frente de uma bateria, onde comanda com graça e cadência cerca de 500 homens e algumas poucas mulheres. Ela domina a arte do samba e do seu próprio corpo. Esse lugar de poder foi arrancado das mulheres negras das comunidades e é um pouco nesse lugar que meu curta pretende chegar. Mas, na verdade, é um filme sobre a realização de um sonho e sobre superação. (Ribeiro, 2016).

Apesar de seus filmes participarem de festivais nacionais e internacionais, chama a atenção para a quase não participação de filmes de cineastas homens negros e mulheres negras nos festivais do Brasil. Sabrina Fidalgo não gosta da denominação "cinema negro", uma vez que, não existe um manifesto ideológico e estético dos cineastas negros e das cineastas negras.

Esse tipo de "carimbo" deslegitima o nosso fazer cinema, pois temos que nos contentar com os pequenos espaços "exóticos" para a difusão dos nossos filmes. Dessa maneira, os filmes não ganham editais, não ganham prêmio de difusão, não são selecionados para os maiores festivais do país, não serão vistos pelos curadores internacionais porque os filmes serão parte de um cinema "étnico". É a legitimação do chamado "exotismo local”, uma das formas mais perversas do racismo institucional brasileiro. (Ribeiro, 2016). 
Sabrina Fidalgo embora reconheça importância da luta política dos movimentos negros, não gosta de estigmas e considera-se mais uma artista do que uma militante.

Lilián Solá Santiago é historiadora, cineasta e produtora. Ela produziu dezenas de filmes e codirigiu com Daniel Santiago o documentário Família Alcântara (2005); com Marianna Monteiro dirigiu Balé de pé no chão, a dança afro de Mercedes Baptista (2006); é também responsável pela direção do curtametragem Graffiti (2008). A cineasta, em 2006, recebeu o prêmio Zumbi dos Palmares, da Assembleia Legislativa de São Paulo, pelo destaque de suas ações de cunho afirmativo "em defesa da promoção da igualdade racial no estado de São Paulo" (Ferreira; Souza, 2017: 179).

Juliana Vicente estudou cinema na Fundação Álvares Penteado (FAAP) e na Escola Internacional de Cinema e TV, em Cuba. Ela dirigiu o curta-metragem Cores e botas (2010), filme que fala sobre padrões estéticos impostos que não condizem com os das mulheres negras. Diretora da Preta Portê Filmes, foi produtora de vários curtas-metragens, também dirigiu o curta-metragem Minas no rap (2015), no qual é discutida a participação das mulheres no rap brasileiro (Ferreira; Souza, 2017: 179).

Jamile Coelho e Cíntia Maria "fazem do cinema de animação um espaço de pertencimento" ao trabalharem com narrativas com enfoque nas identidades e memórias afro-brasileiras. Jamile estudou cinema e audiovisual na Universidade Federal da Bahia (UFBA). Já Cíntia estudou produção executiva na Academia Internacional de Cinema também se graduou em marketing e jornalismo. Elas criaram a série Òrun Àiyé, a criação do mundo (2016); idealizaram e fundaram o Núcleo Baiano de Animação e Stop Motion e são diretoras da produtora Estandarte Produções, na Bahia. Entre os projetos que estão envolvidas, destaco: o segundo episódio da série mencionada e o projeto de animação em 3D, Corações encouraçados (Ferreira; Souza: 2017: 180).

A cineasta Renata Martins graduou-se na Universidade Anhembi Morumbi, fez pós-graduação em Linguagens da Arte na Universidade de São Paulo (USP). Em 2010, lançou seu curta-metragem Aquém das nuvens, filme que "apresenta novas imagens e novos sentidos sobre o envelhecimento para o homem e a mulher negra". Ele foi exibido em alguns países, premiado no Festival UnaSur, na Argentina, e venceu, em 2014, o concurso Televisão da América Latina (TalTV). Em 2012, fez parte da equipe de roteiristas da série Pedro \& Bianca, uma produção da TV Cultura em parceria com a Secretaria da Educação do Estado de São Paulo, a série foi exibida na referida emissora. Lançou em 2015, em parceria com a cineasta Joyce Prado, a websérie documental Empoderadas, cujo objetivo é mostrar histórias de mulheres que atuam em di- 
ferentes campos. A cineasta foi um das roteiristas da temporada de 2017 da novela Malhação, veiculada pela Rede Globo (Ferreira; Souza, 2017: 183).

Eu fiz referências aqui a algumas cineastas negras que estão realizando filme na atualidade. Provavelmente outras, com trabalhos tão qualificados quanto os das cineastas mencionadas, não foram citadas. A minha intenção, nesse momento, foi apenas situar o trabalho dessas mulheres no contexto da cinematografia brasileira contemporânea. É possível afirmar que os cinemas realizados por elas sobrevivem no cenário das produções independentes e que apesar de encontrarem dificuldades para conseguirem financiamentos por vias de editais governamentais, elas vêm contribuindo para a diversificação do contexto cinematográfico atual. Espero que o trabalho dessas e de outras cineastas negras ou não se tornem do conhecimento do público e que as mesmas sejam reconhecidas e lembradas pela historiografia do cinema brasileiro

\section{O problema da não diversidade no cinema brasileiro}

A segunda edição do Boletim Raça e Gênero no Cinema Brasileiro (19702016) ${ }^{6}$ foi divulgado no dia 23 de junho de 2017 pelo Grupo de Estudos Multidisciplinares da Ação Afirmativa (GEMAA), do Instituto de Estudos Sociais e Políticos da UERJ (IESP-UERJ). O estudo em questão analisou a presença de mulheres e pessoas negras nas produções cinematográficas brasileiras de grande público entre os anos de 1970 e 2016. Só filmes de ficção foram considerados na análise.

O referido estudo representa um horizonte temporal maior do que o de estudos anteriores. A partir de dados disponibilizados pelo Observatório Brasileiro do Cinema e do Audiovisual (OCA-ANCINE) foram coletadas as informações de gênero e raça de pessoas que desempenharam as atividades de direção, roteiro e a atuação nas obras cinematográficas. As informações coletadas dizem respeito aos filmes de ficção realizados entre 1970 e 2016 que tiveram um público acima de 500.000 espectadores. A partir da análise dos dados os pesquisadores Márcia Rangel Candido, Cleissa Regina Martins, Raissa Rodrigues e João Feres Júnior chamaram a atenção para uma problemática do contexto audiovisual brasileiro: a desigualdade que este expressa e a ausência de uma diversidade.

Entre os filmes analisados, $2 \%$ foram dirigidos por mulheres brancas, $85 \%$ por homens brancos e $11 \%$ por homens sem a informação sobre etnia. O número de mulheres brancas que dirigiram filme de grande público aumentou entre 2010 e 2016, atingindo a porcentagem de 10\%. As roteiristas mulheres

6. Link de acesso ao boletim: http://gemaa.iesp.uerj.br/boletins/boletim-gemaa-2-raca-egenero-no-cinema-brasileiro-1970-2016/ 
foram apenas $8 \%$. Somente uma mulher negra foi identificada, Julciléia Telles, que assinou com Roberto Machado o roteiro da pornochanchada A gostosa da gafieira (1981). Tratando-se de homens negros que assinaram roteiros de filmes de grande público entre 1970 e 2016, a porcentagem é de $2 \%$. Já a que diz respeito aos homens brancos é de $71 \%$. Os atores negros correspondem a $9 \%$ e as atrizes negras a $2 \%$ (Lima, 2017).

Como demostrei anteriormente, existem cineastas mulheres e negras que estão dirigindo filmes, principalmente, curtas-metragens. No entanto, como o estudo do GEMAA demostrou os filmes de ficção de maiores bilheterias são escritos e dirigidos na sua grande maioria por homens brancos, e os filmes dessas cineastas acabam não chegando ao grande público. Para mudar esse cenário é preciso que existam fomentos para as produções audiovisuais das mulheres e dos negros, para que dessa forma a desigualdade que marca a sociedade brasileira deixe de ser tão evidente no campo cinematográfico.

\section{Mostras de filmes de cineastas negras realizadas em 2017}

A Caixa Cultura de Brasília sediou entre os dias 4e 11 de julho de 2017 a Mostra Diretoras Negras do Cinema Brasileiro. Adélia Sampaio, Lilian Solá Santiago, Yasmin Thayná, Juliana Vicente, Renata Martins e Sabrina Fidalgo são algumas das cineastas que tiveram seus filmes exibidos. Entre eles estavam Amor Maldito (Adélia Sampaio, 1984), Kbela (Yasmin Thayná, 2015) e Rainha (Sabrina Fidalgo, 2016). A mostra também foi realizada na Caixa Cultural do Rio de Janeiro entre os dias 5 e 17 de dezembro de 2017.

Entre os dias 2 e 8 de agosto de 2017 foi realizada a Mostra Empoderadas - Mulheres Negras no Audiovisual, foram exibidas 31 produções (curtas, webséries, vlogs, entre outros). O evento foi realizado na cidade de São Paulo. Empoderadas é uma websérie, conforme o mencionado, criada em 2015 com mulheres negras na frente e atrás das câmeras, é também um coletivo. Para a mostra mais de sessenta produções foram inscritas, a exigência foi a de que a equipe contasse com a participação de pelo menos uma mulher negra. As cineastas negras Keila Serruya, do Coletivo Picolé da Massa e Várzea das Artes (AM); Iliriana Rodrigues, do Criadoras Negras (RS); Thamires Vieira, do Tela Preta (BA); e Renata Martins, do Empoderadas (SP) foram as curadoras da Mostra.

Também em agosto, entre os dias 21 e 25, foi realizado I Encontro de Cineastas e Produtoras Negras, na Universidade de Brasília. A cineasta Adélia Sampaio foi homenageada, um troféu com a sua imagem foi entregue as cineastas que tiveram suas obras premiadas. 


\section{Considerações finais}

Como bem destacam Ceiça Ferreira e Edileuza Penha de Souza (2017: 178) os filmes dessas mulheres cineastas corroboram para criação de um cinema de subversão e de combate "às visões preestabelecidas", os mesmo podem "consolidar uma produção focada na pluralidade, na consciência dos múltiplos eixos de opressão e no exercício de afirmação identitária". Essas mulheres estão assumindo um protagonismo ao participarem das diferentes etapas de realização dos filmes.

De acordo com o já mencionado, essas produções correspondem na sua maioria aos filmes de curta-metragem, e circulam nos nichos do que pode ser chamado de cinema independente. Acredito que ainda não seja possível mensurar com precisão o impacto que essas produções têm gerado no cenário do audiovisual brasileiro, contudo, acredito que elas tenham possibilitado que novas temáticas sejam abordadas, que novos sujeitos, nesse caso as mulheres negras, sejam protagonistas de narrativas e estéticas que dizem respeitos às suas realidades sociais, culturais, econômicas e políticas. Assim como Adélia Sampaio, essas cineastas inspiram e inspirarão os trabalhos de outras cineastas.

Por mais que a denominação "cinema negro" seja refutada por alguns, sua defesa não se limita apenas ao campo estético, mas também assume aspectos no campo político, esse cinema "visa defender e construir um lugar de fala que sobreponha e atualize a herança ancestral às expressões contemporâneas, com referências locais e globais" (Sobrinho, 2017: 163). Nesse sentido, os cinemas dessas mulheres convergem com as lutas que foram e são traçadas pelo movimento negro e pelo feminismo negro. Em linhas gerais, este reivindica o direito de "lugar de fala" das mulheres negras, que desde o período escravocrata vêm encontrando formas de resistência.

A menudo las feministas blancas actúan como si las mujeres negras no supiesen que existía la opresión sexista hasta que ellas dieron voz al sentimiento feminista.Creen que han proporcionado a las mujeres negras «el» análisis y «el» programa deliberación. No entienden, ni siquiera pueden imaginar, que las mujeres negras, así como otros grupos de mujeres que viven cada día en condiciones opresivas, a menudo adquieren conciencia de la política patriarcal a partir de su experiencia vivida, a medida que desarrollan estrategias de resistencia - incluso aunque ésta no se dé de forma mantenida u organizada. (Hooks, 2004: 45 apud Jarbado, 2012: 15).

Gilberto Alexandre Sobrinho no capítulo que compõem a coletânea, lançada em 2017, Feminino e plural: mulheres no cinema brasileiro apresenta uma discussão sobre documentários realizados a partir da década de 1980 que têm como centralidade as mulheres negras. Para o autor, esses filmes promoveram uma "forte visibilidade para as questões da mulher negra, já antecipando 
o chamado feminismo negro" (Sobrinho, 2017: 164). Os filmes documentários engajaram mais do que nunca por temáticas de cunho social e político, as mulheres negras foram um desses interesses: “(...) O que se constata é uma guinada em relação ao feminismo negro, que flexiona a luta política da mulher negra, com suas agendas" (Sobrinho, 2017: 165). Cabe mencionar que os documentários citados pelo autor não foram realizados apenas por mulheres negras, mas também por homens e mulheres brancas. ${ }^{7}$

Ainda sem muita propriedade para falar a respeito, uma vez que não conheço a filmografia estudada por Sobrinho, afirmo apenas que a conjuntura atual, ou seja, a que diz respeito aos filmes produzidos pelas cineastas mencionadas nesse artigo, diferencia-se da dos anos 80 e 90, pois essas mulheres assumem um protagonismo nas narrativas que dizem respeito às suas experiências.

Ainda estamos vivendo um processo marcado por lutas, em diferentes instâncias, que visam acabar com a invisibilidade das mulheres negras. Os cursos de cinema precisam reformular suas estruturas para darem conta de formar profissionais sejam homens ou mulheres com capacidade para contar histórias que rompam com status quo. Em outros textos meus venho enfatizando a questão de que é necessário reconhecer o papel das mulheres em diferentes momentos da história do cinema. A coletânea menciona, organizada por Karla Holanda e Marina Cavalcanti Tedesco, cumpre esse papel, como demais iniciativas que venho presenciando desde 2016 quando comecei a pesquisar sobre o assunto.

Os filmes dessas cineastas negras, assim como o feminismo negro, têm um caráter contra-hegemônico (Jarbado, 2012: 29), e estão contribuindo para a visibilidade das mulheres negras. O cenário ainda está longe de ser o ideal, mas tem que se reconhecer que há um movimento promissor que tenta romper com as barreiras impostas por questões de gênero, raça e classe social.

\section{Referências bibliográficas}

Ferreira, C. \& Souza, E. P. (2017). Formas de visibilidade e (re)existência no cinema de mulheres negras. In K. Holanda \& M. C. Tedesco (orgs.), $\mathrm{Fe}$ minino e plural: mulheres no cinema brasileiro. Campinas, SP: Papirus.

7. Os documentários citados por Sobrinho foram: Mulher negra TV (Ras Adauto e Vik Birkbeck, 1985), Mulheres negras (Márcia Meireles e Silvana Afrom, 1986), Axé (Márcia Meireles e Maria Angélica Lemos, 1988), Orí (Raquel Gerber, 1989), As divas negras do cinema brasileiro (Ras Adauto e Vik Birkbeck, 1989), Eu mulher negra (Joel Zito Araújo, 1994), Almerinha, uma mulher de trinta (Joel Zito Araújo, 1994), Carolina (Jefferson De, 2003), 25 de julho: o feminismo negro contado em primeira pessoa (Avelino Regicida, 2013), Anjo de chocolate (Clementino Júnior, 2013), Sangoma (Daniel Fagundes, 2014), Lápis de cor (Larissa Fulana de Tal, 2014), Kbela (Yasmin Thayná. 2015), Elekô (Coletivo Mulheres de Pedra, 2015) e Mulheres negras: projetos de mundo (Day Rodrigues e Lucas Ogasawara, 2016). 
Fonseca, R. (2010). Com dois longas lançados e vários em andamento, a Cavídeo se firma como núcleo de produção de... O Globo, 28 de julho. Disponível em: https://oglobo.globo.com/cultura/com-dois-longas-lancadosvarios-em-andamento-cavideo-se-firma-como-nucleo-de-producao-de-2 973906

Hooks, B. (2004). Mujeres negras. Dar forma a la teoria feminista. Otras inapropiables. Madrid: Traficantes de sueños.

Jarbado, M. (org.). (2012). Feminismos negros: una antologia. Madrid: Traficantes de sueños/Mapas.

Lima, J. D. de (2017). Um retrato da diversidade no cinema brasileiro das últimas cinco décadas. Nexo, 27 de junho. Disponível em: www.nexojornal.c om.br/expresso/2017/06/27/Um-retrato-da-diversidade-no-cinema-brasil eiro-das-\%C3\%BAltimas-cinco-d\%C3\%A9cadas?utm_source=socialbtt ns\&utm_medium=article_share\&utm_campaign=self?utm_source=socia lbttns\&utm_medium=article_share\&utm_campaign=self

Neto, S. (2015). Fulana de tal: conheça Larissa a diretora negra por trás do filme "Cinzas". Alma Preta, 24 de julho. Disponível em: www.almapreta. com/editorias/realidade/fulana-de-tal-conheca-larissa-a-diretora-negra-p or-tras-do-filme-cinzas

Nicácio, G.(2017). Cinema é sobrevivência. Folha de S. Paulo, 30 de setembro. Disponível em: http://agoraequesaoelas.blogfolha.uol.com.br/2017/ 09/30/cinema-e-sobrevivencia/

Ribeiro, D. (2017). Conheça Viviane Ferreira, a segunda negra a dirigir um longa no Brasil. Carta Capital. 1 de setembro. Disponível em: www.cart acapital.com.br/diversidade/viviane-ferreira-a-segunda-negra-a-dirigir-u m-longa-no-brasil

Ribeiro, S. (2016). Sabrina Fidalgo fala sobre o seu novo curta "Rainha, cinema brasileiro e suas referências como mulher negra. Modefica, 11 de fevereiro. Disponível em: www.modefica.com.br/sabrina-fidalgo-cienast a-brasileira/\#.WiVvxoanHcd

Sobrinho, G.A. (2017). Identidade, resistência e poder: mulheres negras e a realização de documentários. In K. Holanda \& M. C. Tedesco (orgs.), $\mathrm{Fe}$ minino e plural: mulheres no cinema brasileiro. Campinas, SP: Papirus. 